\title{
ALGORITHM FOR SIMULATION OF BLOCKING PROBABILITY IN QUEUES OF TYPE MM1K AND MMKK FOR DATA SERVERS
}

\author{
JULIÁN R. CAMARGO L., MIGUEL A. ÁVILA A., OSCAR D. FLÓREZ C \\ Engineering Faculty, Universidad Distrital Francisco José de Caldas, Bogotá, Colombia
}

\begin{abstract}
This paper presents the development of two functions implemented in Matlab to simulate the operation of a queue in a $M / M / 1 / K$ type server (one server, $k$ users) and another one of $M / M / K / K$ type (k servers and $k$ users) generating the blocking probability in each case. With this information, it is possible to manage the resources that are available to provide service to the different requirements of an organization.
\end{abstract}

KEYWORDS: Matlab, Quality of Service, Queue Theory, Server, Telecommunications Networks

Received: Jun 08, 2020; Accepted: Jun 28, 2020; Published: Sep 16, 2020; Paper Id.: IJMPERDJUN20201277

\section{INTRODUCTION}

Queue theory is the branch of mathematics that studies the phenomenon of client queues waiting to be served by one or more finite capacity servers. The aim of queue theory is to be able to predict the length of the queue, the occupation of the servers, the waiting times of the clients, the rejection rate due to lack of quota, etc., in order to propose analysis, design and control mechanisms [1], [2].

Communication networks are made up of a set of resources with limited capacity that must meet the demands imposed by network users. The dynamic interactions that are formed when users compete or collaborate to use the network resources is the subject of study of the queuing theory. The name is very reasonable considering that, in these cases, a waiting line, or queue, is usually formed by the users who found the requested resource occupied.

Of course, the application of this theory has gone far beyond the scope of communications networks, since it is based on the queuing theory that decisions are made such as how many cashiers to place in a supermarket, how many runways to place in an airport, how many lanes to place in the entry and exit systems of a highway, at what speed to move a supply conveyor belt on an assembly line, how to properly time a traffic light at an avenue crossing, etc. [1], [3]

In telecommunications networks, queues are formed by sharing the bandwidth of finite capacity links, by transmitting packets in time slots over TDM links, by accessing switching structures on cut-through routers, by resolving conflicts in multiple access protocols over shared radio links, etc. At higher levels, queues can be formed on file servers, web servers, cloud processors, etc. Generically we will represent any of these cases in terms of "packages" and "links".

That is, the operational unit that flows through a queuing system will be given the generic name of packet, although it may actually be calls, sessions, connections, flows, service requests, demands, jobs, customers, etc. Likewise, 
we will say that the requested service is offered, in generic terms, by a "link", although in reality it may be a file server, a slot in a TDM link, a web server, a frequency band in a radio environment, etc. [1], [4]

For these cases the same structure can be detected: some packet sequences arrive at a service center, where a certain number of links exist. The packets wish to be transmitted by at least one of the links, but if a packet does not find available links at the time of its arrival, it must join a queue to wait for its turn to transmit. When the packet is selected for transmission, it will be assigned one or more links, or a fraction of the capacity of a link (according to a set of rules known as the "service discipline"). The packet will occupy the allocated resources for a specified time until it completes its transmission (Figure 1). The packet will then be said to have left the system [5]-[7].

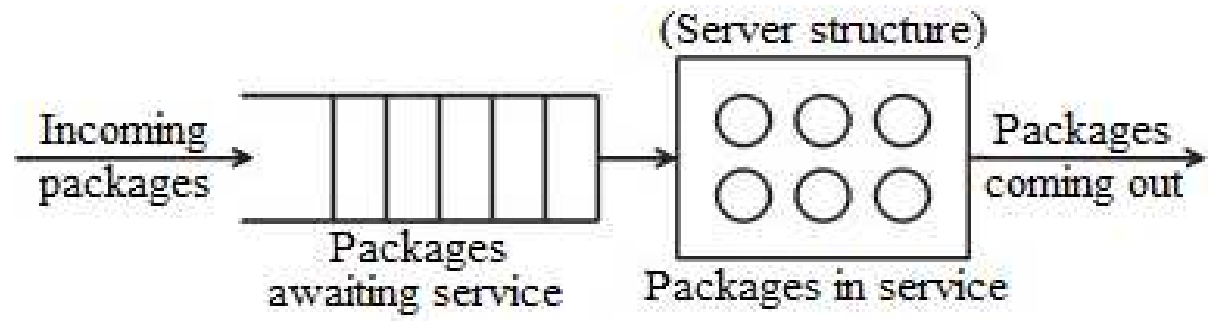

Figure 1: Structure of a queuing system [1]

\section{Features of A Queuing System}

A queue model is characterized by the following elements: (1) a stochastic process A that describes the customer arrival process; (2) a stochastic process B that describes the customer service process; (3) an integer C that represents the number of servers, (4) an integer D that represents the quota or maximum number of customers that can remain within the system; (5) an integer $\mathrm{E}$ that represents the number of potential customers that could request a service; (6) an F mechanism of customer care or service discipline; and (7) a G mechanism for managing quotas in the system or memory management [1], [3].

Kendall's notation refers to the specification of the first three characteristics in the $A / B / C$ format, in which case it is assumed that the quota in the system is infinite, that there is an infinite number of possible clients, that the first to arrive is attended to first, and that the quotas in the system are assigned in order of arrival until they are exhausted. If any of these characteristics are different, the extended notation of Kendall $\mathrm{A} / \mathrm{B} / \mathrm{C} / \mathrm{D} / \mathrm{E} / \mathrm{F} / \mathrm{G}$ is used, as presented in Figure 2 [3], [8].

\begin{tabular}{|l|l|c|c|c|c|c|}
\hline $\begin{array}{l}\text { Arrivals } \\
\text { process }\end{array}$ & $\begin{array}{c}\text { Services } \\
\text { process }\end{array}$ & $\begin{array}{c}\text { Number } \\
\text { of servers }\end{array}$ & $\begin{array}{c}\text { Quotas in } \\
\text { the system }(\infty)\end{array}$ & $\begin{array}{c}\text { Number of } \\
\text { clients ( } \infty)\end{array}$ & $\begin{array}{c}\text { Service } \\
\text { discipline } \\
\text { (FIFO) }\end{array}$ & $\begin{array}{c}\text { Memory } \\
\text { management } \\
\text { (Droptail) }\end{array}$ \\
\hline
\end{tabular}

Figure 2: Features to be specified in a queuing system [1]

The arrivals process refers to the mechanism by which packages are generated at the system's entry. An alternative is that the packets arrive in equally spaced instants of time, one packet every $\tau$ seconds, in which case the arrival rate is constant and corresponds to $\lambda=1 / \tau$ packets per second.

This assumption is represented by the letter D in Deterministic. Of course, this is not a very realistic assumption in modern communications networks, because the arrival of packets is usually at random times. It is then necessary to describe the joint probability distribution of the arrival moments. 
If the arrivals are assumed to be completely random, the times between arrivals will be independent and identically distributed according to an exponential distribution, generating a Poisson-type arrivals process. In this case, as the times between arrivals are exponential and independent, that is, without memory, we speak of M (Memoryless) processes.

In other cases, the times between arrivals can remain independent and identically distributed (iid), but not necessarily exponential. It is possible to speak of GI processes, general and independent distribution, if only some particular statistics are known such as the average value and the variance of the times between arrivals, but not their precise distribution. Or you can specifically model a non-exponential probability distribution such as the Erlang distribution of $\mathrm{k}$ stages, or Ek process, or the hyper-exponential distribution of $\mathrm{k}$ stages, or Hk process.

The third parameter, number of servers, can refer to the number of links, the number of TDM or FDM channels, or the maximum number of users allowed in a CDMA cell so that the ratio of signal power to interference power can ensure a specific error rate. It is an integer that must always be specified. Parameters four and five are simply two natural numbers which, by default, are considered to be infinite. Although a router's memory cannot be infinite, it can be arbitrarily large, given the low price of solid state memories, so the assumption of infinite memory (infinite quota) is not as unrealistic as it seems. Similarly, even though the number of inbound links in a router may be small, each link can bring traffic composed of a large number of users.

The assumption of an infinite number of potential customers refers to this condition, in which the traffic generated by an individual user is negligible compared to the total traffic of all users. If this is not the case, the activation or deactivation of a user can affect the total rate of arrivals and then it will be convenient to consider a finite number of potential customers [1].

Service discipline and memory management are closely related to Quality of Service (QoS) mechanisms in modern communication networks. The service discipline refers to how the link (the transmission resource) is to be signed between the different flows that make up the incoming traffic. The most obvious and simplest discipline to understand is FIFO (Firs In, First Out) or FCFS (First Come, First Served), according to which packets are handled in order of arrival, without considering any additional criteria such as size, origin or priority.

Its great advantage is that it is very simple to understand and implement, but the overall performance of the network can be impacted negatively. For example, if a very large packet (occupying the channel for 10 ms) arrives immediately before a very small packet (which occupies the channel for $0.5 \mathrm{~ms}$ ), the FIFO discipline will make the first packet take 10 $\mathrm{ms}$ and the second packet take $10.5 \mathrm{~ms}$ for an average of $10.25 \mathrm{~ms}$. If the smallest packet were served first, the delays would be $0.5 \mathrm{~ms}$ and $10.5 \mathrm{~ms}$, respectively, for an average of $5.5 \mathrm{~ms}$, a reduction of more than $46 \%$. For this reason, different mechanisms are proposed, such as PQ (Priority Queueing), according to which packets are attended according to an externally assigned priority measure [1], [9].

The last parameter to be specified is the memory management mechanism in the buffer. Normally packages are accepted as long as there is space to store them, and only when the space is exhausted is the first discard produced. These discards will continue to occur until enough memory space is free to accept a new packet. This mechanism is called DropTail - discard at the end of the queue. With DropTail, congestion is notified to users by packet discard when the storage resources have been completely exhausted, i.e., the congestion is first notified when the network is already completely congested [10], [11]. 


\section{METHODOLOGY AND RESULTS}

\subsection{Simulation of the $M / M / 1 / K$ queue with Matlab}

To simulate the M/M/1/K queue (1 server and $\mathrm{k}$ users) the code presented in Figure 3 was implemented in Matlab [12][14].

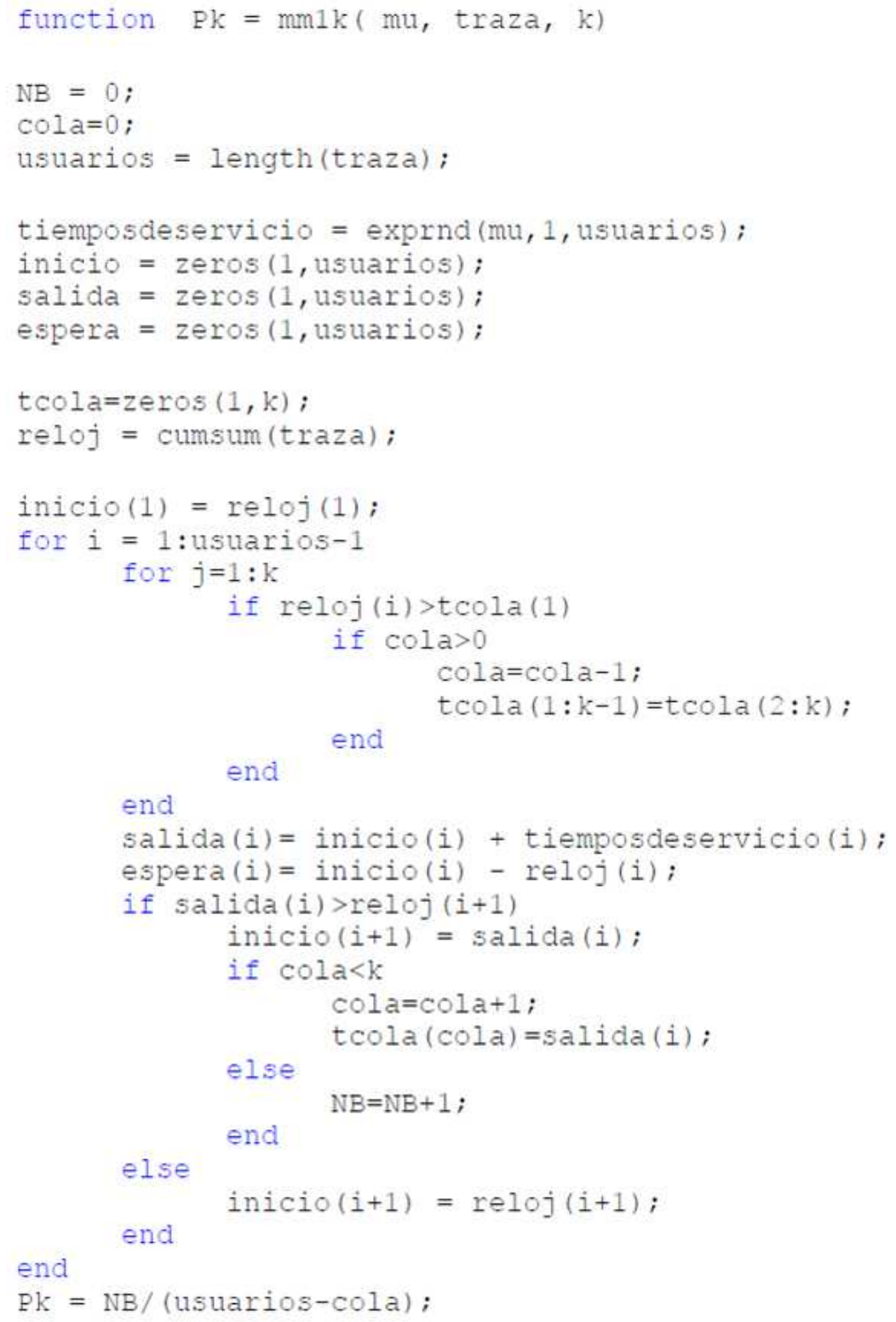

Figure 3: Code implemented in Matlab to simulate the $M / M / 1 / K$ queue

\subsection{Pk vs mu graph for the $M / M / 1 / K$ queue}

To observe the blocking behavior and the confidence intervals of the queue, simulations were performed with 50 iterations of 5000 users for a constant mu parameter value of the exponential probability distribution (Figure 4). 


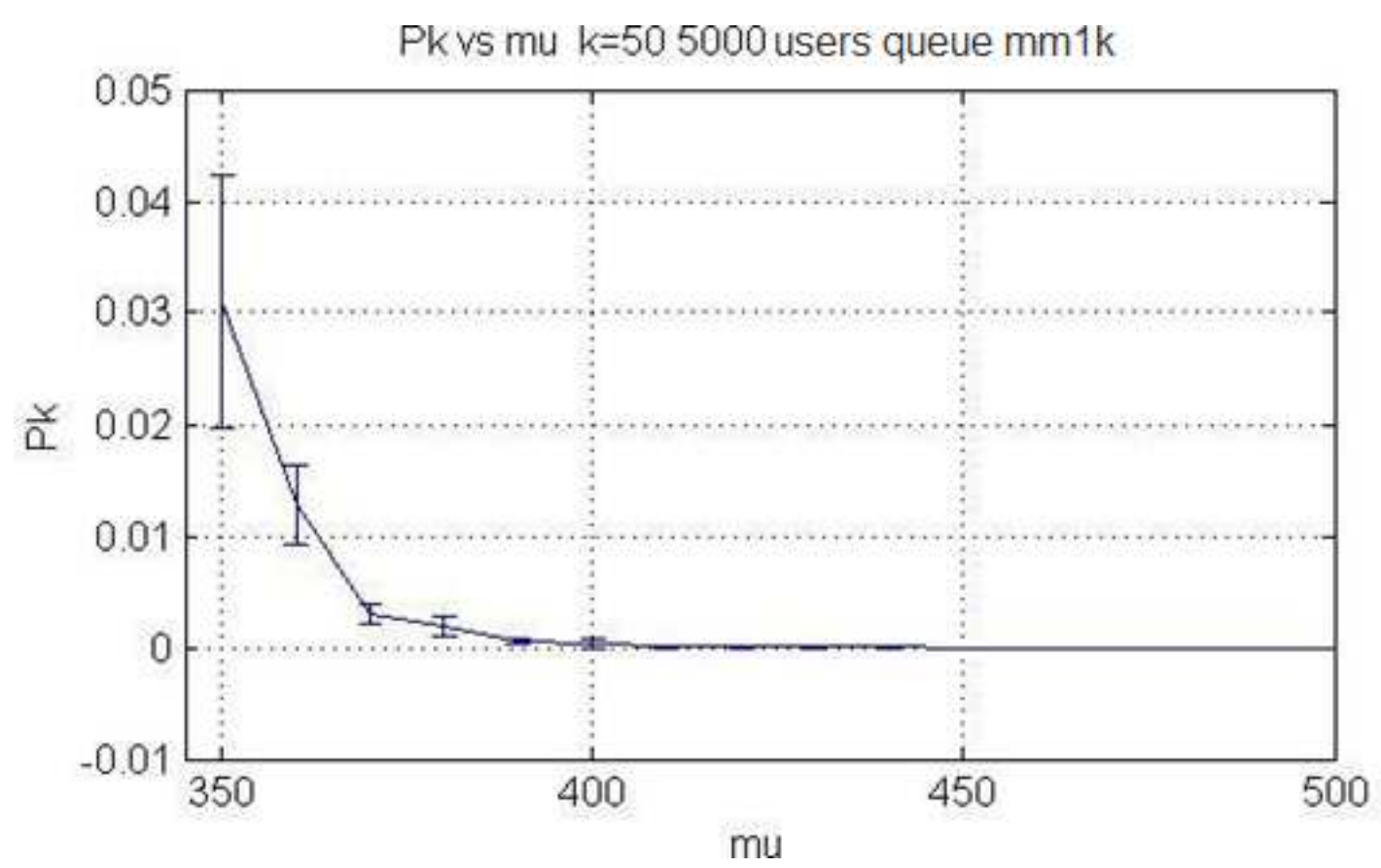

Figure 4: Probability of queuing mm1k against data trace parameter mu $k=50$

Then simulations were performed with 100 iterations of 5000 users for a constant mu parameter value of the exponential probability distribution (Figure 5).

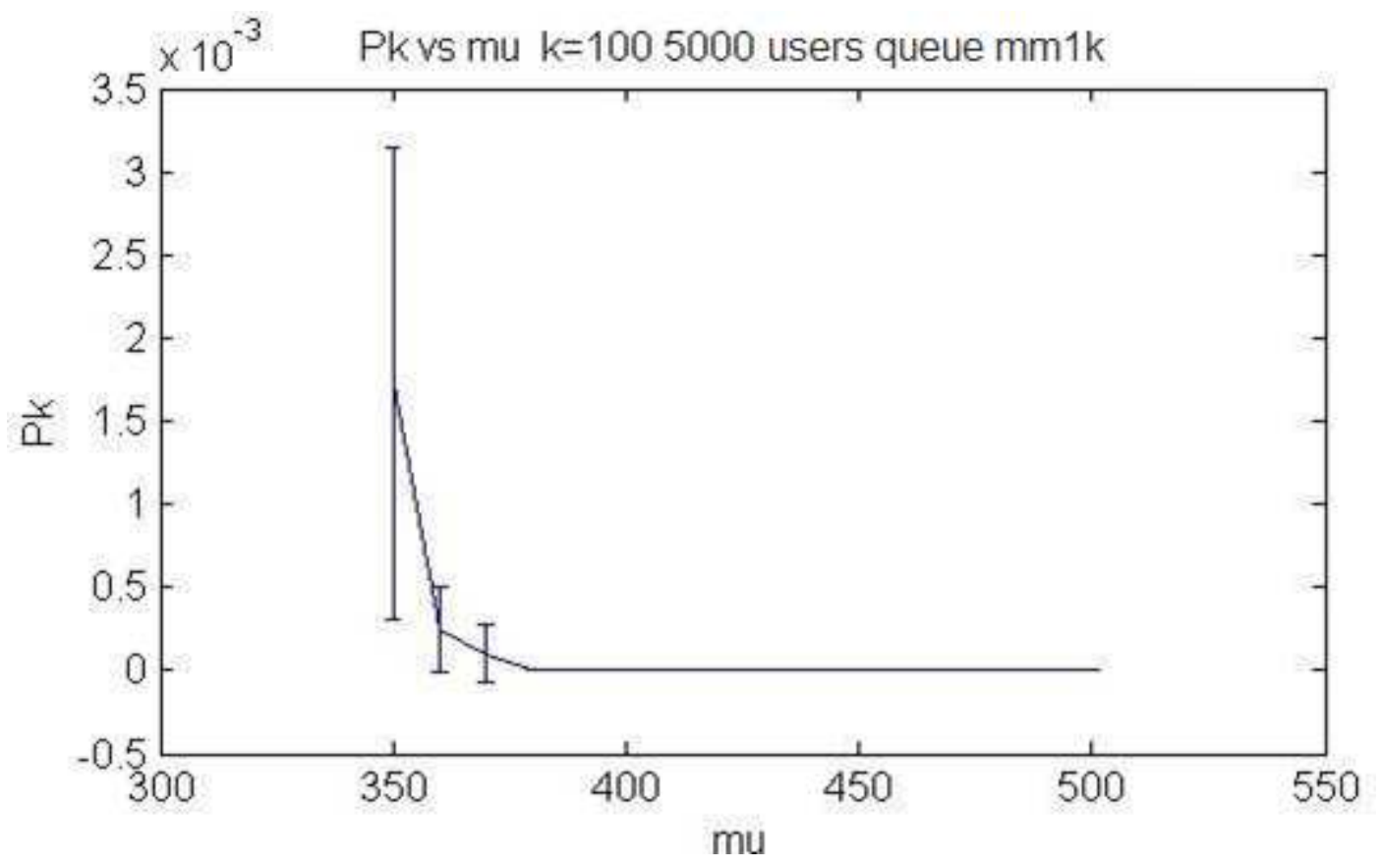

Figure 5: Probability of queuing mm1k against data trace parameter $\mathrm{mu} k=100$

Tests performed with 2000 users for a mu of 350 to 500 and with a k of 5, 15 and 25 can be seen in Figure 6. 


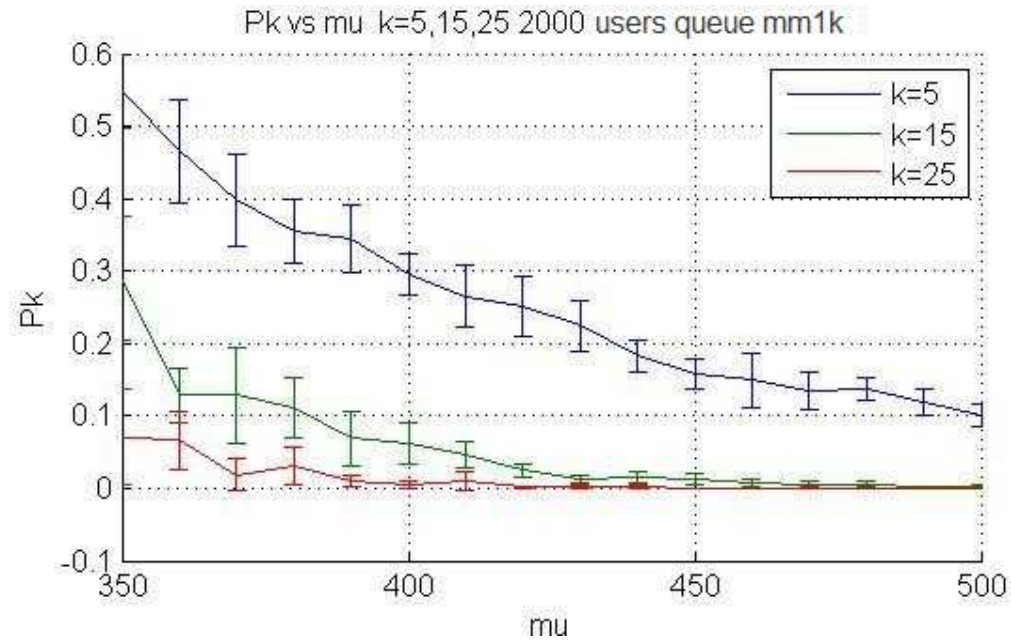

Figure 6: Probability of queuing mm1k against data trace parameter mu with different parameters $k$

\subsection{Results for each of the stages}

To simulate the $\mathrm{M} / \mathrm{M} / \mathrm{K} / \mathrm{K}$ queue ( $\mathrm{k}$ servers and $\mathrm{k}$ users) the code presented in figure 7 was implemented in Matlab.

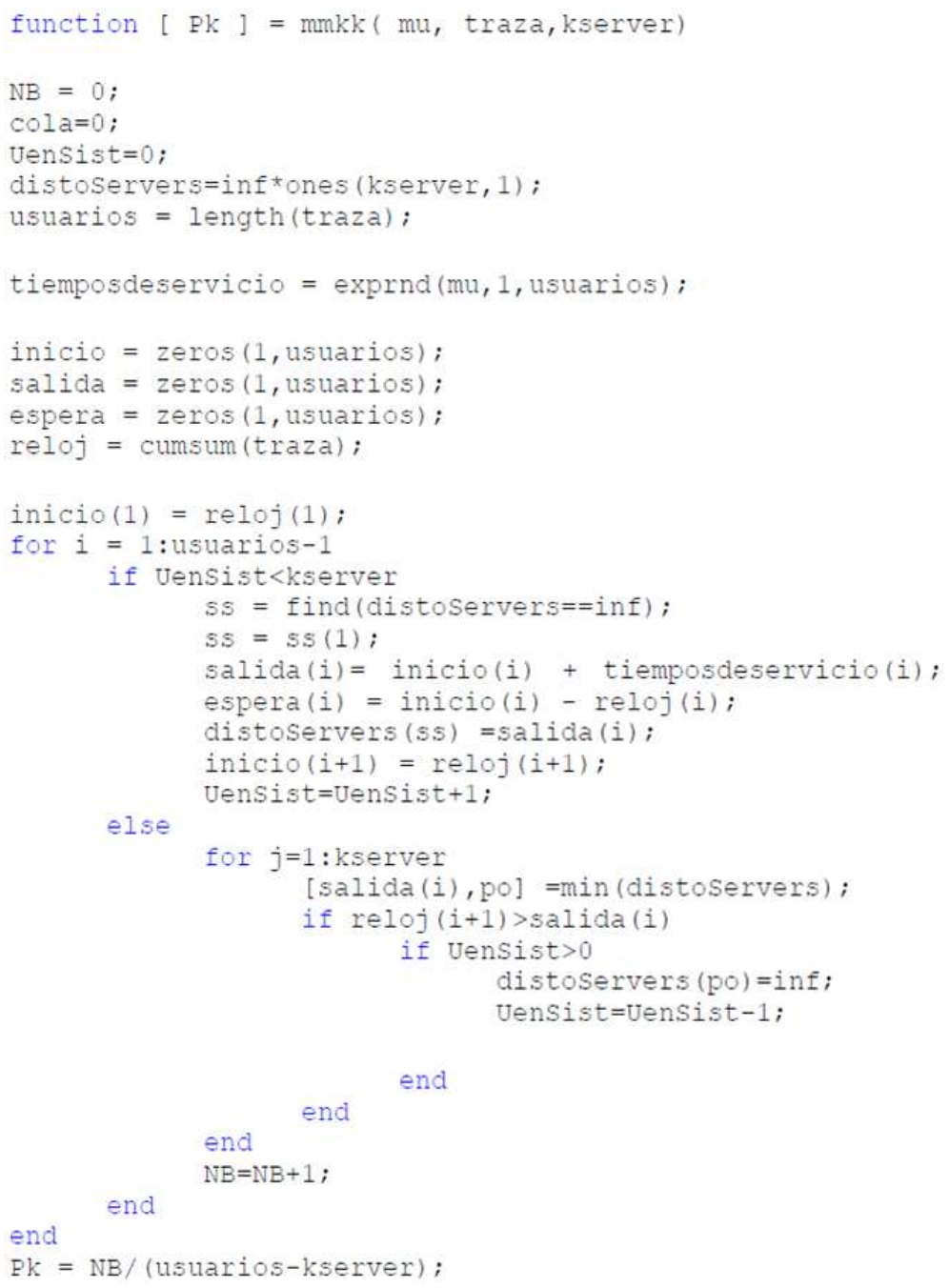

Figure 7: Code implemented in Matlab to simulate the $M / M / K / K$ queue 


\subsection{Pk vs mu graph for the $M / M / K / K$ queue}

The tests with 2000 users for a mu of 350 to 500 and with a $\mathrm{k}$ of 5,15 and 25 performing 10 iterations can be seen in Figure 6, Figure 7 and Figure 8.

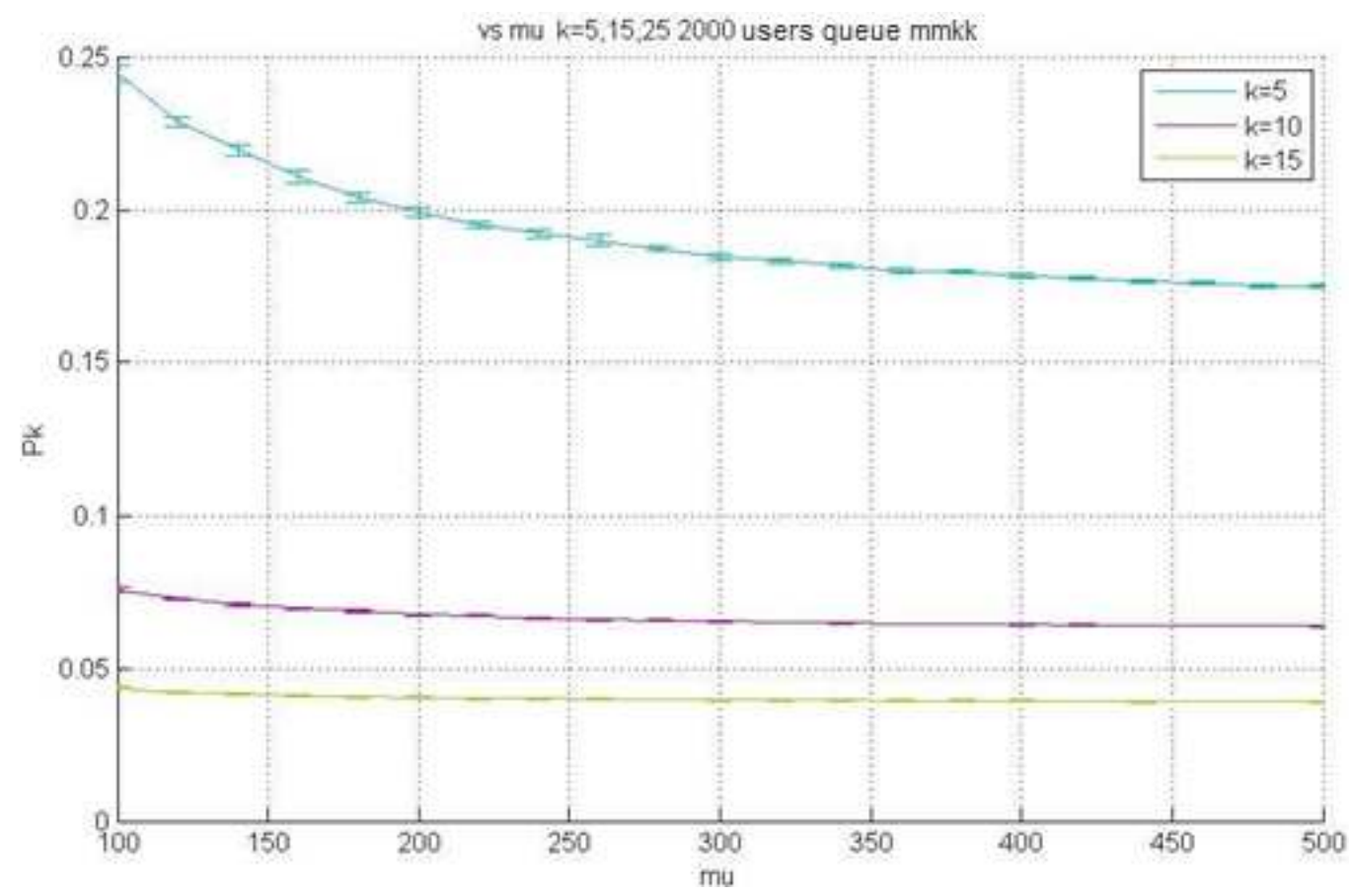

Figure 8: Lockout Probability in Queue Mmkk Against Mu Parameter of the Data Trace with Different K

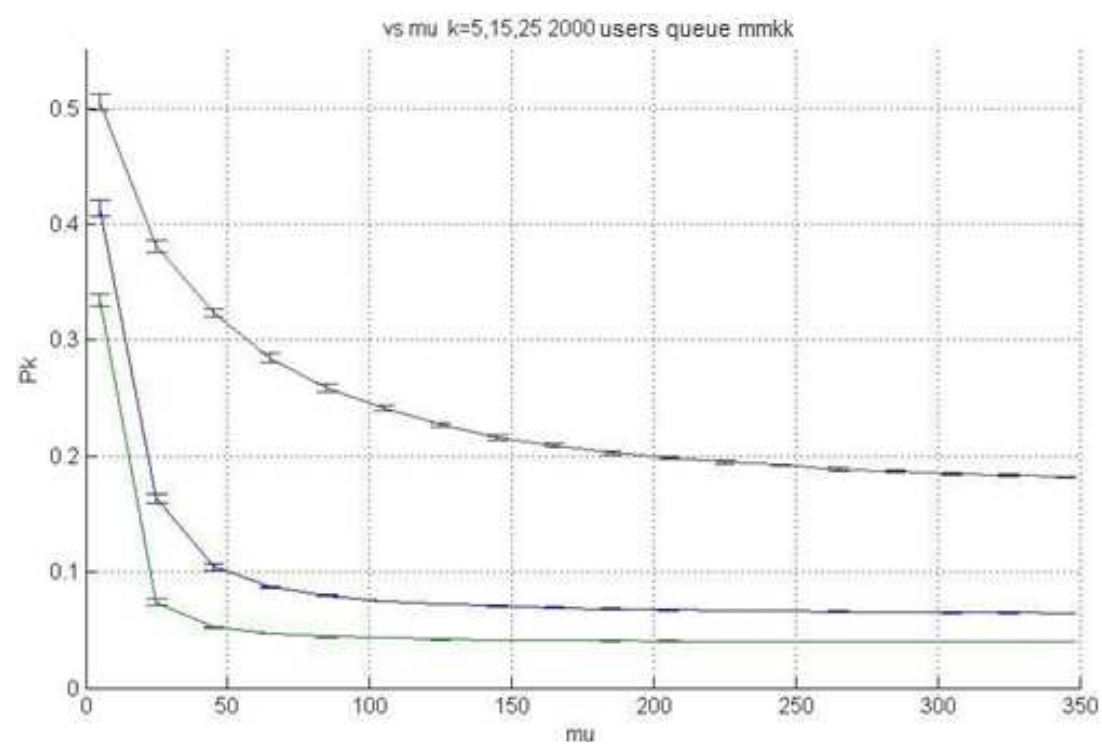

Figure 9: Lockout Probability in Queue Mmkk Against Data Trace Mu Parameter with Different K Values, for Data Trace Using Bellcore 1

Function 


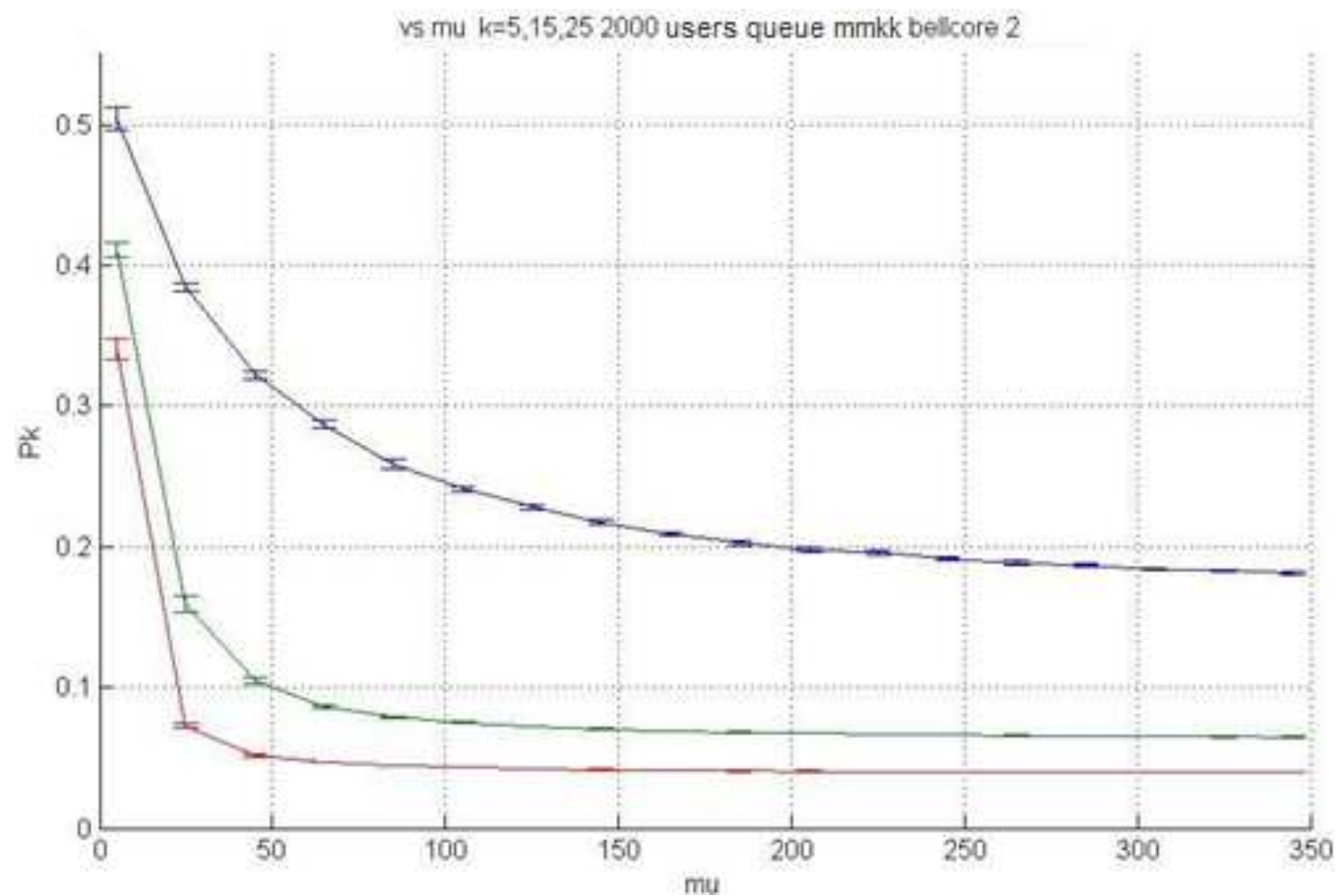

Figure 10: Lockout probability in queue mmkk against data trace mu parameter with different $k$ values, for data trace using Bellcore 2 function

\section{CONCLUSIONS}

It is possible to determine that the $\mathrm{M} / \mathrm{M} / \mathrm{K} / \mathrm{K}$ type of queue is more efficient than the $\mathrm{M} / \mathrm{M} / 1 / \mathrm{K}$, since the probability of blocking in the former is lower than in the latter, with the same number of users.

When analyzing the efficiency of the servers for queues of type $\mathrm{M} / \mathrm{M} / 1 / \mathrm{K}$ and $\mathrm{M} / \mathrm{M} / \mathrm{K} / \mathrm{K}$, it is observed that taking into account the same values of $\mathrm{k}$ the $\mathrm{M} / \mathrm{M} / \mathrm{K} / \mathrm{K}$ queue is more efficient because the probabilities of blocking are lower.

For both cases of the queues, it is observed that when the $\mathrm{k}$ is closer to the number of users who intend to enter the system, the blocking probability tends to 0 , and likewise, at a higher number of mu or service speed, the blocking probability also decreases.

\section{ACKNOWLEDGMENTS}

The authors would like to thank the Universidad Distrital Francisco José de Caldas and the LASER research group that supported the development and testing of the project.

\section{REFERENCES}

1. Alzate, M. A. (2014). 250 Conceptos de Probabilidad, Variables Aleatorias. Retrieved from: http://comunidad.udistrital.edu.co/malzate/files/2014/07/NotasDeClase_Trafico.pdf

2. Gross, D. \& Harris, C. M. (2008). Fundamentals of Queueing Theory.New York: Wiley.

3. García, J. (2015). Aplicando Teoría de Colas en Dirección de Operaciones. Departamento de Organización de Empresas Universidad Politécnica de Valencia, Valencia, España.

4. Tabish, M. O. H. D., M. J. Ahsan, and A. Mishra. "ProbabilityAnalysisforPrediction of AnnualMaximumRainfall of One to 
SevenConsecutiveDaysforAmbedkar Nagar Uttar Pradesh." IJASR 6 (2015): 47-54.

5. Adan, I. J., Boxma, O. J. \&Resing, J. A. C. (2001). Queueing Models with Multiple Waiting Lines. Queueing Systems. 37(1):65-98.

6. Oke, M. O.,Ogunlade,T. O., Fadugba, S. E. \&Adebayo,K. J. (2020). Queueing Model for Optimizing Vehicular Traffic Flow at a Signalized Intersection in a Developing Urban Center. International Journal of Advanced Science and Technology. 29(7):13926-13937.

7. Adeleke,R. A.,Ogunwale O. D. \&Halid,O. Y. (2009). Application of Queueing Theory to Waiting Time of Out -patients in Hospitals. Pacific Journal of Science and Technology. 10(2):270-274.

8. Kiran, R., and S. D. Sivakumar. "Direction of TradeAnalysis of Indian Grapes." International Journal of Business Management \&Research (IJBMR) ISSN (P) (2016): 2249-6920.

9. Alzate, M. A. \& Vega, J. F. (2002). Predecibilidad del tráfico en redes modernas de comunicaciones. Revista INGENIERIA Universidad Distrital. 7(2):21-30.

10. Som, B. K. \& Seth, S. (2018). M/M/c/N Queuing Systems withencouraged Arrivals, Reneging, Retention and Feedback Customers, "Yugoslav Journal of Operations Research,28(3):333-344.

11. Yuan Gao, Guanghui He and Hou, J. (2002). On Exploiting Traffic Predictability in Active Queue Management. In IEEE Infocom 2002, New York, June 2002.

12. Shashikumar, K. T., and M. Pitchaimuthu. "Heterosis and combiningabilityanalysis of quantitative and qualitativetraits in muskmelon (Cucumismelo L)." International Journal of AgriculturalScience 6 (2016): 341-348.

13. Ray, S. S. \&Sahoo, P. (2011). Monitoring of network traffic based on queuing theory. ARPN Journal of Science and Technology. 1(1):1-10.

14. Patidar, L., Bisoniya, T., Abhishek, A. \&Ray, P. (2014). Queuing Theory: A Case Study to Improve the Quality Services of a Restaurant. In International conference (ICIREMPS-2014) under TEQIP-II, SIRT, Bhopal, 2014, pp. 1808-1812.

15. Srivastava, S. K., Chauhan, A. K. \&Pathak, A. (2019). The Deterministic Modeling for Availability and Survivability Evaluation of Avionics Display System Using Markov Model Simulation on Matlab. International Journal of Mechanical and Production Engineering Research and Development (IJMPERD). 9(3):895-902.

16. HANCHATE, SEEMA, S. A. Borsune, and SHIKHA NEMA. "COMPARATIVE STUDY OF PAPR PERFORMANCES FOR DIFFERENT SUBCARRIER MAPPING TECHNIQUES IN SC-FDMA." Int. J. Electron. Commun. Instrum. Eng. Res. Dev.(IJECIERD) 5.1 (2015).

17. Balaji, N., Siva, E. P., Chandrasekaran, A. D. \&Tamilazhagan, V. (2018). Optimal service using Matlab - simulink controlled Queuing system at call centers. In National Conference on Mathematical Techniques and its Applications (NCMTA 18) IOP PublishingIOP Conf. Series: Journal of Physics: Conf. Series 1000, 2018.

18. Singh, N., Sharma, P. \&Kathuria, M. (2017). Modeling and Analyzing the Ber Performance of OFDM-MIMO System with 16-QAM Using OSTBC for Wireless Communication Based on Matlab. International Journal of Electrical and Electronics Engineering Research (IJEEER). $7(2): 63-72$. 

